\title{
Motorbikes against Ho Chi Minh? Or the Consumption Icons of a Social Transformation in Vietnam
}

\author{
ALEXANDRE DORMEIER FREIRE
}

\begin{abstract}
The motorcycle is an unavoidable item in contemporary Vietnam. Since the renovation policy (Doi Moi) in 1986, it has become the most visible consumption good. This article questions the utilitarian and symbolic use that is made of it by the urban populations of Hanoi. This article addresses the question of the values and social transformations within the post-socialist society in Vietnam, symbolized by the consumerism practices of motorbikes. It also explores the process of classification and differentiation and the consumerism significance related to motorbikes. Furthermore, the use of the motorcycle procures some form of intimacy and privacy for people in a society where the state still widely shapes domestic and public spaces. Certain ritual phenomena associated with the use of motorcycles are addressed as well, such as illegal races. These races contribute to the construction of the masculine identity and the article questions whether they are an act of social defiance.
\end{abstract}

Keywords: Vietnam, social transformation, consumerism, motorbikes, social values.

\section{Introduction}

In Vietnam, motorbikes ${ }^{1}$ are literally everywhere and seem to be perfectly integrated into the social and economic life. Even more, they appear to be the icon of the renovation policy launched in the country in 1986, known under the name of Doi Moi, although the introduction of motorbikes into the country goes back to the 1960s when US and Japanese mopeds were imported into South Vietnam. A regular visitor to Vietnam can easily observe the richness and the complexity of social behaviours related to the use of motorbikes in this country. Given the surprising lack of literature ${ }^{2}$ on the sociological aspects of motorbikes in Vietnam, this article is an attempt to deconstruct and analyse this richness as well as a first step towards the comprehension of their sociological role within the society. 
The aim of this article is to understand the behaviours, social statuses and values as well as consumerism significance related to the motorbikes in urban areas of Vietnam. From that perspective, is it possible that in a society in transition like Vietnam, the motorcycle also symbolizes the emergence of new hedonistic values, more individualistic, with which the young urban populations not only identify themselves but also call for? Can the reclaiming of these new values be seen as a form of symbolic violence in opposition to the older generations' values? For instance, are the illegal races of motorbikes, which can be observed at night in cities, a new form of social contestation? What is the social logic behind these races - the construction of a new masculine identity or a form of symbolic violence relating to 'political consumerism'?

People driving by the thousands, during the evening, at the heart of cities or around the Hoan Kiem lake in Hanoi, as well as on the Le Loi Avenue in Ho Chi Minh City, or even these young couples ready to have intimate contact on their motorbikes (which is socially not very acceptable in public spaces). Do people seek, in the use of their motorbikes, some form of privacy and intimacy? In a country where the state still remains rather intrusive in domestic spaces, where the density of the population is high and privacy is scarce and controlled, we could assume that the motorbike is used to enjoy some forms of privacy difficult to find elsewhere.

To understand the social transformations that motorbikes symbolize in Vietnam and to answer the multiple questions above, this article consists of two parts. The first briefly returns to the emergence of mass consumption in the Doi Moi period and proposes some theoretical background and evidence on consumerism, social differentiation and the notion of 'intimacy' or privacy in the use of the motorbikes. It analyses the new social values and practices of differentiation related to the emergence of consumerism in Vietnam. The second part of the article illustrates some consumerist practices and social-related behaviours, such as the emergence of the concept of pleasure, the search for some 'intimacy on the motorbike', and the phenomenon of illegal races. It is based on eight semi-directive interviews with two men and two women under 35 years old, and two men and two women over 35 years old held during January 2007 in Hanoi. The interviewees are owners of at least one motorbike and belong to the middle class of Hanoi. This sample is not representative. People were selected according to the 'snowball' technique. This paper ${ }^{3}$ is not only based on interviews conducted with urban users but also on observations carried out during the numerous stays of the author in Vietnam. 


\section{Background and Evidence on Consumerism, Social Differentiation, Spaces of Intimacy and the Context of Vietnam}

Background: the emergence of motorbikes and mass consumption in Vietnam

Many books ${ }^{4}$ and articles describe the 'miracle' of Vietnamese economic development that appeared with the Doi Moi (renovation) policies launched in 1986. This economic takeoff allowed a general increase in living standards. For example, the GDP per capita rose from US\$ 300 in 1994 to US\$ 750 in 2006. In this new environment, former key economic actors like agricultural cooperatives and governmental enterprises seem to belong to the past. Businessmen are the new symbols of a dynamic private economy, replacing party cadres. A social urban middle-class has developed subsequently. As Philippe Papin (2003: 11) observes, this class remains very much related to the state apparatus, however it does not mean that there is no social transformation affecting the country on all levels. Through its gradual exposure to international brands (through media such as the internet and cable television or through contact with tourists) as well as increased income, the middle class fully entered into the mass consumption society. The accession of Vietnam to the World Trade Organization (WTO) in January 2007 after more than ten years of negotiations is another symbol of the emergence of a market- and consumption-oriented economy.

Among common consumption goods, which best illustrate these transformations, one could point to mobile phones, televisions, and of course, motorbikes. Today, Vietnam counts more motorbikes per capita than neighbouring countries: nearly 169 per thousand inhabitants, against 44 in China and 79 in Indonesia. Nearly 16 million officially recorded motorbikes circulate throughout the country. In 1990, there were only 1.2 million motorbikes in Vietnam. This figure was thus multiplied by ten over a 14 year period although similar motorbikes can be twice as expensive in Vietnam due to taxes applied to imports. Undeniably, motorbikes became one of the most visible goods and a symbol of mass consumption in the Doi Moi society.

\section{Social Differentiation, Values and Consumerism}

'Consumption' and 'consumerism' obviously have various meanings. Each may refer to different theoretical backgrounds and disciplines. 
A general and straightforward distinction can be made: consumption refers to the 'volume and taxonomy of all spending that was in any way potentially variable or discretionary' and consumerism to 'broader motivational drives to consume in particular ways' (Glennie 1998: 928). It can be understood as a focus on meanings and on the construction of 'an independent identity through consumption' (Glennie 1998: 928). As for any definition, the two terms are subject to debate and other notions and concepts have appeared lately in the literature such as 'consumer society' or 'postmodern consumerism' to describe both phenomena.

As any consumption good, the motorbike is first an object of social differentiation and positioning (implicit or explicit). In order to address the phenomenon of social differentiation, Bourdieu proposes a framework in particular related to the questions of distinction and symbolic differences observable in the practices of consumption (Bourdieu 1996). The practices of consumption, 'the choice of the necessary', present the 'habitus of the working class as the learned outcome of their material situation' (Trentmann 2004: 375). In other words, the manner of consuming is statutory and takes part in the social reproduction processes. The distance with the consumed object (e.g. in Vietnam, among the urban populations, one describes the motorbike as something of almost no importance, whereas rural population see it as an 'investment') differentiates people from a certain socio-economic category and marks their social status. The differences in the practices of consumption that one notes here become 'differences in symbolic systems' (Bourdieu 1996).

Baudrillard (1996) offers some additional consideration on social differentiation processes with regards to consumerism. The dimension of a symbolic system is expressed through various practices that Baudrillard refers to as the 'process of classification and differentiation', such as statutory values in a hierarchy (1996: 79). In other words, it is not the object that one consumes but its significance in order to be a member of a society without inevitably feeling its constraints (Baudrillard 1996: 80).

However, consumerism brings different signification. Social relations are driven by hedonistic and individualistic patterns, which are primarily related to modern consumers in a market (Migone 2007). Modern capitalistic markets and societies are characterized by individualistic relations in the sense that the process of exchanges between consumers are impersonal (Simmel 2004). The literature also shows that the emergence of 'modern' consumption not only means the 'growing autonomy of a consumerist mentality' but also the erosion of traditional social relations, as in postmodern consumerism people tend to be more individualistic 
rather than class oriented (Trentmann 2004, 2007). Other sociologists such as Bauman have described consumerism as being part of a new 'liquid society' in the sense that it transcends national identities and territories and modifies identities based on work and locality (Bauman 2001). Consumerism is then driven by 'distraction' (Bauman 2001: 12):

But neither Pascal nor Kierkegaard - not even Max Scheler - could anticipate the advent of consumer society which would transform distraction, once an individually contrived hide-out from fate, into something socially constructed: a society in which 'constantly finishing and beginning again from the beginning' would no more be a sign of monstrosity, but the way of life available to all and the only way of life so commonly available.

The consumer society changes the nature of the construction of social identity. Bauman gives plenty of examples on how social identity and image are reshaped by consumerism processes in a 'liquid society' (Bauman 2005).

Mass production and the capitalist economy have profoundly changed needs, perceptions and attitudes towards consumption practices. Mass consumption is not new per se; it appeared with Fordism. However, the difference between the 'postmodern' mode of consumption and the Fordist one is the hedonistic value to be found in postmodern consumerism. Lebow described the buying of goods as a 'ritual' made for seeking 'spiritual satisfaction and ego satisfaction' (cited by Migone 2007: 177). The literature also shows that since the 1980s consumerism is related not only to accumulation of goods but also to a permanent search for new or unusual experiences modifying social values (Campbell cited by Glennie 1998: 928).

\section{Motorbikes and Consumerism}

A lot of 'values' can be identified in relation to consumerism. Among others, the acceptance that the 'ephemerality' of products is 'better' than their durability may be other key values of consumerism, with as a consequence a permanent unsatisfied and renewed needs triggered by mass consumption practices (Bauman 2005). After the Second World War, Arvidsson (2001) demonstrated in an article that motorbikes (in his case the Vespa) had become the icons of 'youth international culture' linked to a vision of 'lifestyle choice' and hedonistic values.

Notably, Vespas were introduced in South Vietnam in the 1960s along with Japanese and American motorbikes and are now some of the most popular (and expensive) to be found on the market. It is interesting to 
make a parallel between the situations in contemporary Vietnam and in Italy. Arvidsson argues that Vespas are a key component of a new material culture that emerged in Italy after the Second World War (2001: 48):

In many ways, the story of the Vespa supplies an ideal case study: presented as a central component of the material culture of a new, modern, post-Fascist Italy in the immediate post-war years, Vespa soon become something of a fetish for the emerging transnational counterculture.

However, contrary to the Italian case described by Arvidsson, in Vietnam motorbike producers were not capturing the codes of counterculture values but were displaying instead signs and symbols of mass consumption modes. As older role models related to communist values could not prevail anymore as being the only core values of the Doi Moi society, consumerism values have implicitly emerged as being key in contemporary Vietnam. But in a certain sense, one could also argue that they belong to a 'counterculture' because they were clearly opposed to the 'socialist' values. The mass consumption-related values resulted from the success of the Doi Moi policies and have introduced a new form of social control. ${ }^{5}$ Bauman explains the social control and order in a consumerism society (2001: 17): 'The fragility and precariousness endemic to pleasure-and-distraction-seeking life has been reclassified from major threats to the stability of social order into its chief support'. In the case of Vietnam, motorbikes served as the central component of a material and pleasure-seeking culture that emerged with the implementation of the renovation policies in 1986 and served the stability of the social order. For young people it soon became the symbol of an ideological gap between them and the older generation, the former 'citizen model' (promoting an image of a standardized citizen following certain 'socialist values and attitudes' common also in other former socialist countries ${ }^{6}$ ). The consumer in centrally planned economies like Vietnam before 1986 was rather ascetic. The communist consumer 'was being called upon to make sacrifices' in order to focus on the needs of production with the promise, despite recurrent shortages, of a brighter standard of living through meeting the material needs of populations as in many former communist countries (Mazurek and Hilton 2007: 916).

The egalitarianism and the uniformity preached by the authorities through its 'citizen model' are overtaken by the emergence of individual values, consumer society, consumerism, and visible social classification processes, in particular among the young Vietnamese. The younger generation is embracing these new values of consumption, which is also an act of symbolic violence against previous generations. The lack 
of attention to consumption matters was one of the root causes of the collapse of the Eastern bloc (Mazurek and Hilton 2007), and it is certain that after 1989 in order to survive the Vietnamese government had no other choice than to open its economy and society to foreign influences and to welcome market-based mass consumption practices.

Consumption practices are not totally deprived of political significance: certain practices have political content. Thus, buying certain brands or boycotting others has been considered a form of political participation in Western countries. The meaning and effectiveness of this form of political participation as underlined by Stolle et al. (2005: 248)is not clear: 'A growing number of citizens are turning to the market to express their political and moral concerns, but do not tell us whether political consumerism can also be considered as a meaningful or effective form of political participation.'

From that perspective, consumption practices would be in a new arena of political expression giving birth to a 'political consumerism', which certain authors have termed 'lifestyle politics', or seeing 'political meanings in recreational experiences, entertainment choices, fashion decisions, and other personal happenings' (Shah et al. 2007: 219). Certain practices related to motorbikes, such as the illegal races taking place during the night in urban areas in Vietnam, are an expression of both the construction of a social male identity and an act of defiance linked to a political dimension of consumerism. By using a mass-consumption symbol of a pleasure-seeking society inverting the long-promoted ascetic socialist moral values, the 'night racers' also display a tacit political message going beyond simple outlawed practices.

\section{Doi Moi Society and the Motorbikes}

In a society in transition such as Vietnam, the motorcycle symbolizes the advent of new hedonist values, a shift from a culture of discipline towards a culture of pleasure. It translates the desire of the youth to find more urban values, or even 'pop', as illustrated by Thomas $(2004,2002)$, Drummond (2000), Lloyd (2003), or Nguyen Anh Phuong (2006) or like the post-war generations in Italy as related by Arvidsson (2001). In Vietnam today, the youth (60 percent of the population is under 30 years of age) neither experienced times of deprivation (from 1975 to 1986) nor the war periods of the country and they are searching for other lifestyle experiences in a context that has witnessed tremendous changes since 1975. To describe this transition using the values perspective, the motorbike 
reflects the desire of people 'to consume' by expressing a certain form of individualism, which clashes in a sociocultural context rather than tending to reject individual values and behaviours. Hence, except the founding figure of modern Vietnam, Ho Chi Minh, the Vietnamese society does not put forward individuals and does not encourage people to affirm their personalities. The communist regime, in addition, always claimed these national traditions and 'values' and have not created or claimed a radical rupture with history, as the Red Khmers did, for example, in Cambodia. With regards to the emergence of new values, Thomas and Nguyen Bich Thuan (2004:135) evoke the changes among young women, while underlining the role of the state in the modelling of social values:

Asserting its control through purging pleasure, the state's power to define popular culture has a contradictory effect: the state is developing a new relationship with consumers, testing the ground of possibility by simultaneously authorizing and disallowing. Working in tandem with mass culture, a new mass-oriented state has become the mark of the postsocialist era.

As described by these two authors, the state, as a new form of social control, thus tries to incorporate such emergent values in a new mass culture centred on consumerism. Motorbikes belong to this tendency to promote new popular culture enclosing new values of pleasure. They also fit in the emergence of a commercial economy where leisure activities gain a new importance through certain consumer goods (mobile telephones, televisions, motorbikes, etc.). Adam Fforde (2003) mentions another amusing example that fits this pattern: in Vietnam, the market for cosmetic products is one of most important of the region. Its size exceeds that of other Asian countries, which however have higher per capita incomes. Other indicators, such as the increasing rate of divorce, rural-urban migration trends and changes in family structure also show that new values are emerging. The motorbike symbolizes, at least in the urban areas, these social changes.

\section{The Notion of Intimacy on Motorbikes in the Light of Public/Private Spaces}

Regarding the notion of 'intimacy' or privacy on a motorbike, it refers to the discourses on public/private space. Let's reconsider briefly the relations between private and public spaces in Vietnam as a first step before coming to the principal hypothesis claiming that motorbikes are considered by people as places where they can get some intimacy and 
privacy. It was already mentioned that the state remains somewhat intrusive in various social spaces, including family relations. Drummond (2000: 2385) summarizes this phenomenon as follows:

The state's involvement with domestic or private spaces centres mainly around attempts to organize household relations and structure social roles within the family. The state is extremely active in attempts to formulate domestic identity.

The state thus organizes and intervenes in all aspects of social life: in the birth-rate (by family planning), in the private sphere (for example the system of merit for the households in the 1980s, the registration of the households and their members, etc.), and in domestic ritual spaces (each household must have a bust or portrait of Ho Chi Minh, etc.). Private as well as public spaces are places where the state expresses its authority, as Anh Nguyen Pham (2005: 1) indicates: 'Space has often been used as a form of social control and an exercise of power to impose a specific social order.'

What about public spaces? For a common visitor to Vietnam, it is difficult to believe that the busy sidewalks, occupied by all kinds of activities - small shops, sports, French style 'cafés', etc.-were empty before the Doi Moi. The informal sector seized this territory once the Doi Moi was launched, which authorized private trade and profit. Since the 1980s, the public authorities in large cities have tried to limit the too-anarchistic development of activities on the streets. For instance, according to Koh (2004), the decree 36/CP from May 1995 in Hanoi was instigated in the purest style of propaganda campaigns, with posters and audio messages broadcast by the innumerable loudspeakers of the city. The objective was to domesticate activities in public space and to overcome urban traffic. This decree also ended the activities of 35 illegal markets, but these attempts had poor results. Why? Drummond (2000) shows that if private spaces are the places of social reproduction, public spaces belong to the community but are strongly controlled by the state. In public spaces, broadcast messages (by posting or public loudspeakers) and organized events are under the strict scrutiny of the authorities. The appropriation of public space remains tolerable for economic activities (handicraft, 'cafés', informal work, etc.) and even sporting activities or entertainment (such as badminton). But the problem is that today, a victory of the national Vietnamese football team brings many more people into the streets than an official procession, and this type of spontaneous demonstration overlaps with the control exerted by the state. Actually, there are plenty of occasions for people to occupy public spaces. An illustration is the visit of former US President Bill Clinton 
in November 2006, who gathered an unexpectedly large, young and lively crowd on the streets of Hanoi during a private walk close to Hoan Kiem lake, as a real rock star ${ }^{7}$ would do! The appearance of this type of transgressive gathering is related to the 're-appropriation' of public spaces. Perhaps nowadays, as Anh Nguyen Pham (2005) suggests, even if public spaces in the cities in Vietnam do not enjoy the same importance as elsewhere because of their recent existence (which date back to colonial times), the level of control existing before the Doi Moi has disappeared. The same author (Anh Nguyen Pham 2005: 7), supported by others, argues that such spaces become almost sites of contestation:

In many ways the streets and sidewalks in contemporary Vietnamese cities such as Hanoi and Ho Chi Minh City (HCMC) have been sites of continued contestations. On the physical dimension, they are extremely crowded and bustling with activities.... Yet state attempts to impose social order on public spaces in Hanoi and Ho Chi Minh City have often been ignored and resisted by the people in both subtle and blatant ways.

Furthermore, in these two large Vietnamese urban centres there is little or no private space available. For example, population density reaches high levels: 3,500 habitants $/ \mathrm{km}^{2}$ for the capital, and 2,800 for Ho Chi Minh City in the south. By way of comparison, the national average in Vietnam is 250. One of the consequences of these high densities relates to the low living space per capita. Thus, in Hanoi, each person has only $5 \mathrm{~m}^{2}$ of habitable surface; it is approximately $6.2 \mathrm{~m}^{2}$ in Ho Chi Minh City (Guidebooks to French Co-operation in Vietnam 2002). In comparison, in Geneva people have on average $47 \mathrm{~m}^{2}$ (Statistique de Genève 2000) and $30 \mathrm{~m}^{2}$ in Paris.

It seems that there is a noticeable contradiction: private space is deprived and strongly controlled, and public space is almost a place of quasi-contestation. Where is the motorbike in this contradiction? The assumption of this article suggests that because spaces of intimacy are rare, motorbikes would be places where people could have some privacy without feeling the constraints of the domestic space.

\section{The Motorbikes and the Doi Moi Society: New Values and Places of Intimacy?}

A tool of multiple purposes and an object of social classification More than a simple tool for transportation, certain Vietnamese even consider them 'as their legs!' according to the expression of one of the persons met in Hanoi. The interviewees confirm that all their journeys, 
even short ones, are carried out on motorbikes, easily beating any other transportation means, including walking. As a consequence, in urban arteries the flow of traffic can reach up to 10,000 bikes per hour.

In one of the very rare comparative analyses between various countries (Vietnam, Taiwan and Malaysia) available, the author Hsu TienPen (2003: 22) affirms that Ho Chi Minh City inhabitants and Hanoians respectively make 3.0 and 2.6 trips per day on their bikes, against 2.2 in Manila, 1.7 in Jakarta and 2.3 in Bangkok. According to Kengo Mizuno and Naohiro Kitano (2000: 137), the most used means of transportation would be the motorbike with nearly 95 percent and 92 percent (of journeys) for Hanoi and Ho Chi Minh City respectively, the remainder being distributed between car, taxi, bus and other means of transportation. In Bangkok and Jakarta motorbikes account for only approximately 25 percent of trips. Compared to other countries, motorbikes are more used in Vietnam. There are no huge differences in the public transport infrastructures between these various cities (except for Bangkok). On the contrary, Hanoi and Ho Chi Minh City have a decent network of reliable and affordable buses, unlike some large Indonesian cities, for example. In other words, the use of the motorbike in Vietnam is related to a variety of activities, whether economic, social or recreational, explaining the above-mentioned daily travel figures.

For poorer households, the motorbike is seen as an investment and is used as a tool to increase their incomes. The motorbike is like a 'Swiss multi-functional pocket knife' for its multiple applications: it is used to transport any kind of merchandise, ${ }^{8}$ or to provide a service to people (xe ôm), a very popular solution for travel within urban areas. Nguyen Xuan Dao and Nguyen Huu Duc (2003:3) have highlighted the importance of motorbikes as economic instruments: in Vietnam motorbikes serve not only as transportation, but as a means to earn income by transporting products.

The mobility provided by the motorbike is obvious and it has contributed to improved access of farmers to markets and has played therefore an important role in the diversification of rural activities. Another example of a rather unexpected motorbike 'service delivery' is prostitution. Thus, in Hanoi, on Pham Ngu Lao and its adjacent streets close to the opera and Trang Tien str., prostitutes come in the evening to look for possible pedestrian or motorized customers. Once hooked, the prostitute takes the customer along to cheap hotels on the other side of the bridge in the Gia Lam district. There is, hence, a multitude of observable activities pursued on motorbikes. But only a 
few studies exist that measure the exact role of motorbikes in income generation.

As said earlier, in low-income or rural households, people generally describe their two wheels as an 'investment'. In this respect, it is interesting to note the difference in perception between them and the urban sample of this article composed of wealthier social classes for whom motorbikes do not constitute an economic tool or an investment. The wealthier social classes depict their motorbikes as a usual or sometimes even as a 'fashionable' device. Linh, a 25 year-old young woman met in Hanoi, first says that all her family members have a motorbike, except her little brother. And she makes it immediately clear: 'We use it to go to work, but do not work with it!'

If motorbikes remain an object of social classification, an 'investment of economic value' for some, a simple fashion item for others, the forms of social distinction and the consumerism significations have also evolved in urban areas. For sure, the price, the brand and the model count. But as a 'lifestyle' object in cities now, it is not enough to travel around on a shimmering Japanese scooter. To emphasize a social status, people customize their bikes, and in doing so they do also express certain individualistic and pleasure-seeking values linked to modern consumerism. Thus, customization reinforces the image of a fashion device for young urban classes by adding value and meaning and distances them from its utilitarian dimension. The youngest female respondents have, on an average, repainted their motorbikes twice in one of the many specialized shops located on Cao Ba Quat or Hue streets in Hanoi. Each new colour costs nearly US\$ 250 to 300, according to the model. To affirm themselves as 'urban', young women follow the 'trend' of the moment, which animates the streets of Hanoi, from pink, to white, red, and nacreous white today: 'I have only two friends who have the same model as me, and nobody has it in this colour!' claimed one young female respondent. But colouring is not enough. Nowadays, some subtle decorative details, such as representations of flowers or dragons come to embellish and further customize the motorbikes, to make them, eventually, even more unique and to accentuate a distinction, a status, and a social class flag.

For male respondents under 35 years of age, the customization process operates differently as it is partly linked to the phenomenon of illegal races. They usually replace parts of the engine and add accessories to win either on power or on 'stability' according to the expression used by Cuong and Linh. Men regret that the scooter models take an increas- 
ingly important place compared to standard motorbikes, since 'they are unusable to race' and they regard them as 'motorbikes for women'.

There are significant generational differences. Young motorbike owners, both male and female, are keen on spending considerable amounts for their two wheels, but the elder interviewees do not have the same social behaviours. One among them, Hahn, 50 years old, doesn't see the utility and the fun of spending money for his motorbike, apart from the gasoline. His example shows well the shift existing at this level between generations. Those under 35 (the 'post-war' generation) spend on average more than dongs 200,000 (US\$12.5) per month for maintenance and customization, against a few thousands for the elders.

The amount spent for the purchase of a motorbike can reach very high levels compared to living costs, especially among younger people. Thus, Cuong (24 years old), an office clerk earning approximately US\$ 180 per month, with the assistance of his family, spent almost US\$2,200 to get a Yamaha Exciter. This example proves that the whole family seems somehow to benefit from the symbolic capital and social status of such an acquisition. If motorbikes are common objects on the streets of the country, displaying an expensive one returns a positive image and acts as a social marker. Likewise, another 44 year-old woman, owning a modest $50 \mathrm{~cm}^{3}$ scooter, whose price hardly exceeds US $\$ 900$, reported that some of her relatives lecture her by saying that her motorbike does not reflect her social position (she is working in a foreign higher education institution and holds a Ph.D.).

These few stories, taken from interviewees, confirm what one can read in popular Vietnamese newspapers. Hence, the press has widely reported the story of a minister's daughter who diverted money from her parents to offer six of her friends the same scooter she had, a Honda Dylan, costing US\$ 5,000. The people interviewed for this article drive motorbikes whose value ranges between US $\$ 2,200$ and 5,000. This confirms the trend that from 80 percent in 2001, the low-cost motorbikes represent less than 50 percent today in urban areas (Courrier du Vietnam 2007). Each of the interviewees has a recent model; the notable exceptions were a man and a woman aged above 35 years, the only ones to own basic and cheap bikes. The age factor of the interviewees indicates already some differences in the social behaviours, demonstrating differences in the social values between generations.

Twenty years ago, before the Doi Moi, no one would dare to display ostentatious signs of richness, whereas today, there's no embarrassment. To drive a US\$ 5,000 motorbike becomes a desirable and statu- 
tory behaviour. In certain cases, the origin of the money used to acquire motorbikes, which in the case of Cuong for example represents several years of wages, remains turbid. Admittedly, households have savings and sometimes remittances (reaching approximately two or three billion US dollars per year at the national level). People may also have several jobs or income activities. But it is likely that a part of these sums comes from corruption-related activities or from the underground economy. Finally, it does not matter; no one seems to attach any importance to it. The amounts spent on some consumption goods (motorbikes, mobile telephones or televisons) are almost acts of symbolic violence with respect to the old generations and values they conveyed. Thus, for the 'old guard', these new behaviours can be experienced almost as a provocation, or at least as a deviance compared to the 'citizen model'.

\section{Some Intimacy on Motorbikes?}

One of the assumptions of this article is that people see the motorbike as a place where privacy could be found and that the generalization of the use of motorbikes has enabled urban people to express new behaviours within the context of the above-mentioned lack of space. This assumption is supported by the figures given at the beginning of this article on the high number of daily journeys made by the Vietnamese.

The interviews confirm a certain number of points: first of all, motorbikes appear to be important in the search for some intimacy. All users mention that being on a motorbike offers the 'luxury' of isolation. Thus, several people choose the motorbike to find some privacy, 'to think', 'to reflect' and even 'to depress' or 'to cry'. Moreover, it goes without saying that the motorbike is a privative space where people can converse freely. A young woman even affirms that the motorbike is 'a more open' space to discuss than a café, for example. The way it works is quite simple: one takes on board a person with whom he or she maintains relations of proximity. The choice of the person who sits behind the driver is thus based on the nature of the relationship, a strong tie according to Mark Granovetter (1973). Often, these 'chat tours' are done with intimate people and confidants. The destination of the tour has hardly any importance, even if respondents acknowledge preferring to drive in very crowded places such as the large avenues of the Hoan Kiem lake, located in the historical heart of the city.

The topics discussed during these tours can vary, but concern intimate topics, as says a young female respondent: 
I often chat on the bike with my cousin; we speak about family, work, marriage. It is the atmosphere on the motorbike, which is pleasant to discuss: we drive, we see people, and we get some fresh air. In fact, work and love are the topics that I discuss more often with my cousin. We'd rather talk on the bike than in a coffee shop because it's less crowded.

However, the nature of the conversations can also be more casual. It is worthwhile noting that among the interviewees, the youngest have expressed more intensively these perceptions of intimacy and freedom. Here again, we can observe the emergence of new values among the younger generations moving away from what is preached by the authorities. Thus, it is hardly surprising that the oldest respondents do not share this enthusiasm, arguing that it is 'sad to drive all alone' or that the motorbike 'does not represent a place of intimacy or privacy'.

The motorbike becomes a place to liberate certain frustrations difficult to express elsewhere, like a 35 year-old woman who confessed 'to kiss other boys, to speak about my husband', while other respondents answered 'When I feel stressed or sad, or want to cry, I take a ride on my motorbike'. It seems that the use of motorbikes allows individuals to express themselves differently. This is applicable to men and women under 35 years, but much less, again, for those who belong to the older generation. Here the age factor plays an important role in the social behaviours related to the use of motorbikes. Undeniably, the motorbike significations vary between older and younger generations, the latter expressing not only 'pleasure-seeking and distraction' values but also 'social freedom'.

While walking around in the streets of Hanoi, particularly at night, one can easily observe the couples holding each other while driving on the motorbike. At traffic lights, one can distinguish the younger couples fondling. Occasionally, couples can even be spotted kissing and cuddling in the dark around the numerous lakes around the city or in parks. This is particularly striking, since it is uncommon for people to show signs of affection in the streets. It illustrates the perfect integration of the motorbike in the 'modern and urban' values and lifestyle, as flirting on motorbikes is a widespread practice. The bike became a place or a tool and a symbol of libertinage. Among the younger respondents, the practice of flirting on the bike is quite common. Nonetheless, not all the respondents share such flirting practices on the motorbikes and there is a certain sense of limitations on the perception of the privacy offered by the motorbike. Thus, a young woman emphasized that she doesn't do anything more than she does elsewhere in public. Signs of affection in a public place are impolite for her. People above 35 years give less importance to the 
motorbike as a flirting place and device, yet without rejecting it. Here again the gap between generations is clearly observable.

\section{Motorbike Races at Night, a Form of Social Contestation and Identity Construction}

Motorbike races are a common phenomenon in Hanoi (seemingly less in Ho Chi Minh City) and concern primarily young men. There are no studies available on the subject. The following lines are an attempt to describe a rather undocumented phenomenon. Yet, it is totally by coincidence that the two young men, Cuong and Linh, met in Hanoi, rather quickly agreed to discuss it, and even showed their scars caused by accidents during races. Revealing their gashes so ostentatiously during the interviews, adopting 'masculine postures and attitudes' such as smoking intensively when speaking about the races, are various signs indicating that this practice is related to the construction of a male social identity similar to a ritual of passage between the end of adolescence and the beginning of adulthood. During the discussion with the two young men, races were often associated with alcohol and their 'gang' of friends converging towards a rite of passage analysis.

How are the races organized? First of all, they are held almost every weekend, between ten o'clock in the evening and one o'clock in the morning, or after an important event or a social celebration, such as the victory of the national football team. (For example, in December 2008, after the first-ever victory of Vietnam in a regional football competition, a large crowd of motorbikes gathered in the city with, as a consequence, 65 accidents and several dead in few hours.) 'Alcohol is mixed with a pleasure feeling' says one of the two young men referring to hedonistic values and unusual life experiences. Often, the mobile phone is used to fix an appointment with friends. Races are also organized simply by waiting for other runners at a corner of one of the city's main streets, and 'it is enough to drive around to find other racers'. The codes are clear: one seeks a glance to start the discussion then the racers look for a street to begin the race. Generally, racers drive through the city with friends in search of other racers and compete with unknown drivers, almost never with people considered 'friends'. Cuong, the youngest of the two, uses the term 'gang' in English to indicate that the races are done between 'gangs'. Races are sometimes almost like a code, or a ritual, to mark the membership of a gang. 'When I hang around with my friends, we all do 
races' says Cuong. Certain places where the races take place are more interesting than others: 'Hoan Kiem is to show off, the true races are done in Ba Trieu or Dao Co Viet', tells Linh (all these places are located in the downtown area). Thus, it seems that dissensions exist between those who describe themselves as the 'genuine runners' and the others who are perceived by the first ones as imitators. For the sake of 'balance', the pilot takes a co-pilot (a close friend) on the back seat. Speeds exceed $100 \mathrm{~km} / \mathrm{h}$ even in downtown areas and 'when one falls, the motorbike skids over thirty meters' explains one of them. In certain races, some bets are placed even if the bets do not constitute the principal incentive for the runners. Accordingly, only one of the two openly admitted to having bet up to one million dongs (approximately US\$ 70) for a race.

As we initially assumed, the practice of races falls under a logic of identity construction for young males. Hence, Linh, the oldest of the two, 30 years and an engineer, talks about the races using and emphasizing carefully the past tense. That way, he clearly shows that he is not a 'young man' but a grown-up adult. As a preamble to our discussion, Linh stressed that the races concern 'youngsters' and that he himself, a married man and a father, does not take part in it anymore. Conversely, Cuong uses the present tense when he talks about this topic. The difference is noteworthy. Both men evoke bluntly the reasons for which they have participated in these races: 'to affirm themselves' and 'to show off'. The notion of pleasure also emerges in the discussion. In addition, it evokes the construction of the identity by imitation: 'because others did it', argues one of them. In other words, it is possible to consider these races as a way for young men to affirm their masculine social identities. And they do so with a motorbike, the symbol of new emerging values.

As mentioned previously, races are illegal and they refer to a certain political dimension of consumerism described in the introduction. Thus, taking part in such 'races' is also an act of defiance towards the authorities: 'to tease the police' as the two young men claim. Provoking the police force is a rather widespread practice. One can easily observe in the evening what happens when a traffic light turns red and when police officers stand nearby. Certain young people do not respect the red light in a very ostentatious way. This particular use of the motorbike, symbol of the opening of the country, is rather singular as a means of contestation. Already in the 1990s, quiet and unusual gatherings were taking place on some avenues in Ho Chi Minh City on Saturday evenings: groups of young people drove around, silently, at the same speed, always taking the same itinerary. It's impossible to 
say if all that was organized or spontaneous, and what was the nature of the political content if any. But in any case, it was a manner of claiming more opening, which occurred with the lifting of the US embargo in 1994 eventually. There is no doubt that the races have partly to do with the same social pattern. Certainly it is an expression of a message from a generation wishing to move away from the 'citizen model' that the regime has promoted for many years. In order to do so they use a consumption good, a symbol of social changes - the motorbike-like the youth have done in other places around the world.

\section{Conclusions}

This article on the use of motorbikes and its consumerism practices by urban populations enables us to understand some outstanding features of the social changes that have taken place in Vietnam since 1986. First, the motorbike is the 'economic tool' of the Doi Moi, the symbol of the reforms and the economic transformations recognizable everywhere in the country. Second, the motorbike is an object of social classification conveying new values such as pleasure and hedonism, demonstrating that the former communist country has entered into a 'pleasure-seeking' and 'distraction-oriented' phase as a society linked to the market economy. Third, the motorbike is perceived as a place of intimacy but also, and somehow paradoxically, it must be 'visible' so that social marking can be effective. Fourth, the motorbikes belong to the lifestyle of a young urban generation claiming other values and 'unusual experiences' than those promoted by the previous generations. The way in which they have been appropriated by the youth shows that a gap exists between the image of the 'citizen model' that the authorities still try to promote and, on the other hand, the claims of those who see in their motorbike a means of claiming other values. These various points strengthen the feeling that the motorbike became a kind of 'liberal, libertine and libertarian' symbol for a category of the population, making it possible to break certain social constraints, although as evidence on consumerism theories suggests, it also introduced a new form of social control.

This article is an attempt to describe a wide range of social behaviours related to motorbike consumerism. Thus, it was not possible here to fully discuss the entire range of social practices, such as the illegal races, whose construction of male identity and political consumerism or 'lifestyle politics' remains to be further analysed. However, the ritual of the races shows that the underlying symbolic use of the motorbike 
differs according to sexes: races for men, and displaying urban and 'pop' values based on appearances for women. Nevertheless, such an osmosis with a technological object is astonishing and definitely deserves further research, for it perfectly reflects the social forces at stake in Vietnam.

\section{Dr. Alexandre Dormeier Freire is a senior lecturer at the Graduate Institute of International and Development Studies, Geneva, Switzerland (alexandre.freire@graduateinstitute.ch)}

\section{NOTES}

1 The motorbikes (xe may) existing in Vietnam have small engines with a cylindrical capacity of $150 \mathrm{~cm}^{3}$ maximum. These machines can develop an interesting weight/ power ratio, which enables them to reach decent speeds. They include motorbikes of Vespa type or scooters (i.e. with a flat bottom). Big-engined bikes are quasi nonexistent in the country because their importation remains particularly regulated and their price prohibitive, and the road infrastructure not adapted. Old 'vintage' Russian motorbikes (Minsk) are also to be found but are mainly popular among foreigners or can be spotted in rural areas. Vietnam assembles most of the motorbikes that are available in its market.

2 The questions of traffic and its consequences, particularly in terms of accidents, are the only aspect relatively well covered by the literature (such as Linh C. Le and al. 2002). This is why I will not look further into these aspects here.

3 I wish here to express my gratitude to Dr Alessandro Monsutti (Graduate Institute of International and Development Studies) and Dr Philippe Papin (French School of the Far East) for their valuable comments and contributions to this text, and to Ms My for her kind help in Hanoi.

4 To mention only one of them here, see for example Melanie Beresford and Dang Phong, Economic transition in Vietnam (2000).

5 Social control through consumerism practices has been widely described in the sociological literature, notably by neo-Marxist authors such as Adorno, Horkheimer and Marcuse. They considered mass culture and new forms of consumption practices at the centre of social control. Reification was to become a main characteristic of modern industrial societies leading to the alienation of human beings.

6 The 'socialist morals', just like the mass culture, cannot be separated from the influence of Confucianism in Vietnam. In this respect, see in particular the articles of Philippe Papin or see Alexandre Woodside 1983, 'The Triumphs and Failures of Mass Education in Vietnam.' Pacific Affairs 56(3): 401-27.

7 Clinton remains particularly popular in Vietnam because he is the American president who standardized the bilateral relations between the two countries. He lifted the embargo in 1994 and was also the first US president to return to Vietnam (in 2000) since the end of the war. An example of Bill Clinton's popularity: 'There are no words to describe how happy I am', shouted 17-year-old Nguyen Thu Hang . . clutching Clinton's freshly signed autograph. 'I'm going to frame this and hang it on my bedroom wall!' (CNN, December 2006).

8 The famous photographic book of Hans Kemp called Bikes of Burden nicely illustrates this aspect. For a quick look: http:/ / www.bikes-of-burden.com 


\section{REFERENCES}

Arvidsson, Adam 2001. 'From Counterculture to Consumer Culture: Vespa and the Italian Youth Market, 1958-1978'. Journal of Consumer Culture 1(1): 47-71.

Asia Times Online 2007. 'Vietnam's Restless Youth Rev Up' [online]. Available from: http:/ / www.atimes.com/ [accessed 22 January 2007].

Baudrillard, Jean 1996. La société de consommation [The Consumption Society]. Paris: Coll. Folio, Gallimard.

Bauman, Zygmunt 2001. 'Consuming Life'. Journal of Consumer Culture 1(1): 9-29.

- 2005. Liquid Life. Oxford: Blackwell Publishing.

Beresford, Melanie and Dang Phong 2000. Economic transition in Vietnam: trade and aid in the demise of a centrally planned economy. London: Edward Elgan.

Bourdieu, Pierre 1996. Raisons pratiques: Sur la théorie de l'action [Practical Reason: On the Theory of Action]. Paris: Coll. Points Essais, Seuil.

CNN, 2006. 'Admirers Mob Clinton in Vietnam' [online]. Available from: http:/ / www. cnn.com [accessed 2 December 2006]

Drummond, Lisa 2000. 'Street Scenes: Practices of Public and Private Space in Urban Vietnam'. Urban Studies 37(12): 2377-91.

Fforde, Adam 2003. 'Culture and Economy: Dyed in the Wool Tiger?'. In L. Drummond, and M. Thomas (eds). Consuming Urban Culture in Contemporary Vietnam. London: Routledge.

Gainsborough, Martin 2002. 'Political Change in Vietnam: In Search of the Middle-Class Challenge to the State'. Asian Survey 42(5): 694-707

Glennie, Paul 1998. 'Consumption, Consumerism and Urban Form: Historical Perspectives'. Urban Studies 35(5-6): 927-51.

Granovetter, Mark 1973. 'The Strength of Weak Ties'. American Journal of Sociology 78(6): 1360-80.

Guidebooks to French Co-operation in Vietnam 2002. French Urban Development Activities in Vietnam. Hanoi: Ambassade de France.

Kemp, Hans 2003. Bikes of Burden. Hong-Kong: Visionary World Publication.

Kitano, Naohiro 2000. 'Recent Studies on Urban Sector Issues in Vietnam - Urban Development and Housing and Urban Public Transportation'. JBIC Review 1: 131-35.

Kitano, Naohiro, Kengo Mizuno 2000. 'Urban Public Transportation in Vietnam - Improving Regulatory Framework'. JBIC Review 1: 136-40.

Koh, David 2004. Wards of Hanoi. Singapore: ISEAS.

Le Courrier du Vietnam 2007. 'Les acquisitions de motos en hausse' [Motorbike acquisitions are increasing] [online]. Available from: http:/ / lecourrier.vnagency.com.vn/ [accessed 31 January 2007].

Linh C. Le, Pham V. Cuong, Michael Linnan 2002. Vietnam Profile on Traffic-Related Injury: Facts and Figures from Recent Studies and Their Implications for Road Traffic Injury Policy. Paper presented at the conference 'Road Traffic Injuries and Health Equity Conference', Cambridge.

Lloyd, Kate 2003. 'Contesting Control in Transitional Vietnam: the Development and Regulation of Travellers Café in Hanoi and Ho Chi Minh City'. Tourism Geographies 5(3): 350-66.

Mazurek, Malgorzata, and M. Hilton 2007. 'Consumerism, Solidarity and Communism: Consumer Protection and the Consumer Movement in Poland'. Journal of Contemporary History (42)2: 315-43.

Migone, Andrea 2007. 'Hedonistic Consumerism: Patterns of Consumption in Contemporary Capitalism'. Review of Radical Political Economics 39(2): 173-200.

Anh Nguyen Pham 2005. Public Spaces, State-Society Relations, and Planning in Vietnam. Paper presented at the 8th 'International Conference of the Asian Planning 
Schools Association', Singapore.

Nguyen An Phuong 2006. 'State-Society Relations in Contemporary Vietnam: An Examination of the Arena of Youth'. Asia Pacific Viewpoint 47(3): 327-41.

Nguyen Xuan Dao, Nguyen Huu Duc 2003. 'Study on the Ownership of Motorcycles in Vietnam'. Draft Paper for 'Eastern Asia Society for Transportation Studies', Bangkok.

Papin, Philippe 2003. Viêt-Nam : Parcours d'une nation [Vietnam: the Course of a Nation]. Paris: La Documentation Française, Editions Belin.

Shah, Dhavan et al. 2007. 'Political Consumerism: How Communication and Consumption Orientations drives Lifestyle Politics'. Annals of the American Academy of Political and Social Science 611: 217-34.

Simmel, Georg 2004. The Philosophy of Money. London: Routledge, 3rd Edition.

Statistiques de Genève 2000. La Ville de Genève vu par le recensement : ménages et conditions d'habitation [Household Survey and Living Conditions in the City of Geneva]. Ville de Genève: Genève.

Stolle, Dietlind et al. 2005. 'Politics in the Supermarket: Political Consumerism as a Form of Political Participation'. International Political Science Review 26(3): 245-68.

Thomas, Mandy, Bich Tuan Nguyen 2004. 'Young Women and Emergent Postsocialist Sensibilities in Contemporary Vietnam'. Asian Studies Review 28: 133-49.

Thomas, Mandy 2002. 'Out of Control: Emergent Cultural Landscapes and Political Change in Urban Vietnam'. Urban Studies 39(9): 1611-24.

Trentmann, Frank 2007. 'Citizenship and Consumption'. Journal of Consumer Culture 7(2): 147-58.

-2004. 'Beyond Consumerism: New Historical Perspectives on Consumption'. Journal of Contemporary History 39(3): 373-401.

Tien-Pen Hsu 2003. A Comparison Study on Motorcycle Traffic Development in Some Asia Countries - Case of Taiwan, Malaysia and Vietnam. The Eastern Asia Society for Transportation Studies (EASTS): Tokyo. 